\title{
Intuitive expertise: Theories and empirical evidence
}

\begin{abstract}
Intuition has been long seen as an element of effective human performance in demanding tasks (i.e. expertise). But its form, constitutive elements and development remain subject to diverse explanations. This paper discusses these elements and explores theories and empirical evidence about what constitutes intuitive expertise, and offers an account arising from a review of these explanations. Commencing with a consideration of examples of intuition from distinct fields of working life, it uses a cognitive perspective to open up the discussion for theorizing about intuition from an information processing perspective. It evaluates the widely acknowledged theory of two systems of information processing that proposes two parallel operating systems: the rational and intuitive. This theory provides foundations for understanding experts' abilities to act intuitively in highperformance-level activities. Research on expertise, finally, opens an educational perspective on intuition, with the progression from novice to expert being understood as an enduring and long-term learning process that inherently generates intuitive capabilities. The paper concludes by returning to and making connections with the literature on workplace and professional learning to provide insights into how individual and social learning processes support the development of intuitive expertise.
\end{abstract}

\section{Introduction}

In recent years, intuition has been a hot topic in the popular as well as scientific literature, where it has long been the focus of empirical inquiry, speculation and theorisation. Some authors now promote a daily-life understanding of intuition as being the hidden power behind successful decision-making across a range of activities (e.g. Osho, 2002; Robinson, 2006); whilst others describe, in popularly accepted yet scientifically based accounts, intuition's contribution to high levels of performance in professional areas (e.g. Gigerenzer, 2007; Gladwell, 2005; Klein, 2003; Myers, 2002; Sadler-Smith, 2010). Scientific accounts are now presenting revised, new and empirically informed accounts of intuitive decision-making's efficacy in an increasingly wide range of applied fields (e.g. Asvoll, 2012; Atkinson \& Claxton, 2000; Chudnoff, 2013; Eisenkraft, 2013; Gilovich, Griffin, \& Kahneman, 2002; Kinchin, Cabot, \& Hay, 2008; Plessner, Betsch, \& Betsch, 2008; Sinclair, 2011). Yet, these bodies of literature have their sources in diverse academic disciplines and discourses, including those from educational, managerial and psychological fields of inquiry. Consequently, as intuition is a concept used across disciplines it is important to be clear about how it is conceived within these disciplines and differs across them, particularly when, as here, there is a concern to understand its form, potential and development for making professional practice more effective.

Intuition is usually defined as the capability to act or decide appropriately without deliberately and consciously balancing alternatives, and without following a certain rule or routine, and, possibly, 
without awareness (Harteis, Koch, \& Morgenthaler, 2008; Hogarth, 2005; Kahneman \& Klein, 2009). It is commonly held to permit rapid reactions that result in effective outcomes. That is, it supports the rapid and effective performance of tasks, and not only for those largely requiring quick reaction times (e.g. as in sport), but also in rapid response to complex and urgent problem-solving scenarios, such as those undertaken by emergency room medical practitioners (Harteis, Morgenthaler, Kugler, Ittner, Roth, \& Graf, 2012). Yet, other examples illustrate the diversity, scope and potential of intuition. Klein (1998) describes how firefighters make crucial decisions when under considerable time pressure and without the time to engage in conscious introspection and analysis. When engaging in emergency situations, they report not even being aware of their decision making; just perceiving the necessities for action and describing their responses as (almost linear) reactions to the situation. Undoubtedly, laypersons when involved in such incidents would probably feel the need to consciously engage and decide amongst various courses of action and, potentially, become overwhelmed by the extent of task, and if pressed to perform, may well experience dissonance. Experienced firefighters, however, seemingly apply rich cognitive resources without needing to resort to conscious considerations or extensive awareness of the situation. It is this difference between inexperienced and experienced persons that indicates intuitive expertise likely arises as an outcome of, at one point in time, conscious learning processes. However, to date, little is known about how best to support the development of intuitive expertise. Gladwell (1999), in a New York Times essay, identified some shared characteristics of professional performances of a surgeon, the famous ice hockey player Wayne Gretzky, and renowned concert musician Yo-Yo Ma. These characteristics are that they: i) constantly perform on an extraordinary high quality level and ii) act quickly and often very surprisingly which accounts for their professional competence. Further, Gladwell (2005) describes a situation in 1983, when the Getty Museum received an antique statue and experts' intuition played a role in commencing a process that ultimately led to it being declared a fake. Even though assessment reports documented and vouchsafed the authenticity of the statue, some experts doubted about its authenticity, and these doubts were ultimately confirmed. Yet, when asked, these experts could not identify the source of their doubts: they just described feeling that something was wrong with the statue and its documentation. Then, in January 2009, a US Airways aircraft collided with a flock of geese just after taking off from New York's La Guardia airport. The pilot Sullenberger became a hero, because he decided within seconds that because the engines had failed and could not be re-started to carry out a difficult aviation manoeuvre: to land a large passenger aircraft in the Hudson River. Instantly, after realising he had lost forward propulsion, he made a series of decisions without considering and balancing details of the situations, and through successfully landing the plane in the Hudson River he saved almost 200 lives of his passengers and crew members (Sadler-Smith, 2010).

Together, these cases demonstrate the importance of intuitive processes for extraordinary kinds of occupational performance. However, they also indicate there are different kinds of intuitive 
actions. More than comprising sportspersons' quick reactions, or professionals addressing very nonroutine situations effectively, intuitive behavior also includes the enactment of activities that had not been practised and rehearsed. In this article, we aim at providing a systematic discussion of theories and empirical studies on intuitive expertise to derive conclusions that can inform professional learning processes. In doing so, we are drawn to a statement about intuition made some time since by Reber (1989) that captures well the situation we are seeking to advance:

There is probably no cognitive process that suffers from such a gap between phenomenological reality and scientific understanding. Introspectively, intuition is one of the most compelling and obvious cognitive processes; empirically and theoretically, it is one of the processes least understood by contemporary cognitive scientists (p.232).

It is proposed here that there are distinct kinds of intuitive actions supporting high levels of performance of different kinds. Yet, across them arise the common elements of highly learnt procedures and informed strategic capacities that, together, support the capacity to act intuitively and with great effect. In elaborating these points, this article discusses the theoretical approaches and their empirical evidence from an educational viewpoint. The case is made in the following way. First, the relations between intuition and work performance are discussed, drawing on examples from diverse domains of occupational practices. Then, as perhaps the most predominately informing discipline, the cognitive account of intuition is explained. A key explanatory account of intuitive action within this discipline is the dual system of information processing. However, alone this processing capacity offers an insufficient explanation as intuition is also founded upon other attributes including strategic capacities, to perform actions aligned with performance requirements for the particular circumstance and that this performance arises without recourse to conscious deliberation or through that which occurs below humans' conscious awareness. The account concludes with some suggestions about opportunities for educational interventions to support the development of intuition.

\section{Intuition and work performance}

The illustrative examples of intuition referred to above might infer that its potency is restricted to quite a narrow, yet exotic, range of occupations: emergency aid, professional team sport, surgeons, artists, and pilots, and quite particular performances within them. Other studies verify the value of intuition for effective professional performance in these and a range of other occupations. Crandall and Getchell-Reiter (1993) detail nurses caring for premature babies who seemingly recognised intuitively very subtle changes in these babies that were essential to an early, but necessary, detection of sepsis. Klein (2003) proposes that these nurses' capability was founded in their rich repertoire of experiences in observing babies suffering and dying from sepsis. These experiences subsequently led them to decision making supported by partly unconscious processes and partly by mental simulations, concluding that intuition "is the way we translate our experiences into judgments and decisions" 
(Klein, 2003, p. 13). Abernathy and Hamm (1995) compiled an entire book about surgical cases where intuition supported quick, spontaneous, non-discriminating, yet appropriate decision making. Studies of team sport report similar and consistent findings. In appraising the crucial qualities of extraordinary team sport professionals, Janelle and Hillman (2003) concluded that mental capabilities of intuitive decision making mark the distinction between more and less effective players. They based their findings on authentic citations from the field:

I have heard NHL players joke about players who excel in fitness testing. They are in such great shape but can't compete on the ice. A different skill is required. The quality that separates the exceptional players from the less talented is the ability to make effective decisions under pressure (Janelle \& Hillman, 2003, p. 46f.).

In a similar study, Myers (2002) refers to Mark McGwire (a baseball player) and Kobe Bryant (a basketball player) as examples of athletes acting intuitively: "Don't bother to ask ... Mark McGwire, Kobe Bryant, or Wayne Gretzky how they do it. They couldn't articulate what they know. They just know" (Myers, 2002, p. 150). In addition to the study of firefighters described above, it is plausible that in every domain of emergency service work, the time and opportunities for considering and balancing available options are very limited. It is often crucial that these and other professionals make appropriate decisions almost spontaneously and then act similarly to secure their goals. In emergency medicine, studies conducted by both Hall (2002) and King and Mcleod Clark (2002) highlight the efficacy of intuitive decision making in these roles, as does Lephronon and Patel's (1995) investigation of emergency nurses who rank priorities under time pressure and with limited information. These authors also demonstrated that, like other emergency care workers, these nurses made appropriate decisions without engaging in extensive appraisals of problem resolution options.

Of course, when considered against other forms of work, these kinds of professional domains might be considered as being quite extraordinary. However, there is no reason to assume that intuition is not utilised being across all forms of work, although not recognised in the same ways. That is, intuition is probably a relevant and important attribute for most, if not all, fields of occupational practices that requiring instantaneous decision making. Whether involving the choice of routes taken by taxi drivers, or the problem-solving strategies of car mechanics, many kinds of work performance require such kinds of decision making. Indeed, the requirements for effective performance in occupational practice are increasing perhaps across all forms of work (Billett, 2006). Most countries with advanced industrial economies have needed to increase their competitiveness, and as a consequence the adaptability and flexibility of their work and ways of working. If they ever existed, the idea of distinct divisions of labour and lock-step (i.e. synchronised) work processes have become out-dated in many and likely most workplaces and forms of work (Beck, 1995), including those of professions. In this work environment, decision-making responsibility has been, by degree, transferred 
from managers to those who perform work tasks in workplaces. The main purpose for these changes is to enable enterprises to flexibly react to market and customer demands that are constantly changing as part of the globalisation of economic activity that brings with it increased competition and the need to constantly adapt to changing requirements, technologies and ways of working (Billett, 2006). Thus, workplace demands for employees in almost all occupational fields are increasing and becoming less fixed (Glastra, Hake, \& Schedler, 2004). It follows that workers in all occupations now need to respond effectively to complex situations even when faced with incomplete or seemingly contradictory information. These situations require the making of "hot" decisions, i.e. those requiring intuitive actions (Fischhoff, 2002). So, more generally, the ability to engage effectively without recourse to conscious decision making appears to be an element of the work of waiters (Beach, 1993) and drinks attendants (Billett, 1993), not to mention driving a motor vehicle, to take an even more common example. Hence, the exercise of intuition is potentially relevant to the performance requirements of most, if not all, occupations. However, the majority of the research literature informing our understandings of intuition refers to or has focused on the professions and particularly where (extraordinary) performance is required as a matter of public interest. Yet, there is a broader base of literature that also informs about intuition, what it comprises and its potency for human performance. It is, therefore, helpful to consider this literature to identify processes that inform the development and enactment of intuitive action.

\section{Cognitive theories of intuition}

Early theoretical accounts in psychological thought provided bases for a consideration of and focus on cognitive aspects of intuition. For instance, Jung (1923) proposes intuition as a basic mental function of holistic perception and refers to the assumptions of Spinoza and Descartes who regarded intuition in a philosophical way: as holistic insight. Similarly, Weston (1927) defined intuition as "perception, not so much of theories as of sense regarding the matter in hand" (p. 28, emph. i. o.), to explain individuals' capacities to variously predict economic developments or to detect lies. He also suggests there may be an antagonism between rationality (i.e. reasoned and informed consideration of options) and intuition and even went as far as offering the proposition that females have more intuitive capacities than males because "women are more responsive, while men are more prone to reason" (Weston, 1927, p. 22). Psychological theories of intuition remain an important element of its analyses and established the cognitive view on intuition as a process of specific perception and thinking (Wescott, 1968). Authors from philosophical disciplines complemented these discussions with the phenomenon of rumination and incubation which results in apparent sudden insight, without conscious or even deliberate reflection (Levinas, 1973). Importantly, Reber (1993) claims that unconscious processes, such as intuition, antedate development of conscious thought. Hence, they are likely to be 
central to a range of cognitive functions and sources of human development (e.g. Lakoff \& Johnson, 2003). However, as these processes are not readily accessible through conscious means (i.e. recall in interviews or surveys), they tend not to be the focus of either empirical work or informed discussion. Indeed, Reber (1993) holds that "the conscious awareness that individuals have about such implicitly acquired knowledge is only a small portion of the total knowledge available to them for guiding behaviour" (p. 34). He also claims that:

... from this evolutionary perspective, a number of fairly strong conclusions about the cognitive unconsciousness are easily reached. Firstly, virtually every interestingly complex organism will be endowed with a powerful, covert, information gathering system that has critical epistemological functions. Second, the neurophysiological structures that form the functional foundations for this implicit system are evolutionarily ancient and antedate those that subserve the explicit, conscious systems (p.40).

He concludes that this implicit learning is marked by four features: i) it occurs naturally (i.e. ordinarily) when an organism attends to a structured stimulus display; ii) it largely occurs in an absence of conscious attempts to learn; iii) the resulting knowledge base (i.e. what is learnt and cognitive experience) is held tacitly and unconsciously; and iv) the tacit knowledge that is learnt is abstract. All these precepts support the view that rather than intuitive action being restricted to extraordinary performance by select group of high-performing individuals, they may be more commonly applied and across a wide range of human activities including many, if not most, forms of work.

More recently, the ability to scan activities within the brain is providing greater understandings of processes that individuals cannot declare as these are now able to be mapped. Indeed, it has been proposed that the two hemispheres serve different types of functions: intuitive (i.e. right hemisphere) and analytic (i.e. left hemisphere) activities (Hogarth, 2001). Neurosciences, supported by these new technology capacities, can analyse the involvement of specific areas of the brain in particular actions (Damasio, 2012; Frank, O’Reilly, \& Curran, 2006), thereby opening up understandings about how such processes are progressed cognitively. For instance, increasingly, representations in human memory are seen as being richly interlinked with associated forms and together these are referred to as simulations (Barsalou, 2003), and these are ordered through particular categorical forms. Yet, not only are these representations premised on these categorical forms, but also how they are subsequently recalled and utilised. Barsalou states the

... conceptual system comprises knowledge about the world, which is categorical by nature. It is not a collection of images of the sort that a camera or video recorder or audio recorder captures. Instead, a conceptual system is a collection of category knowledge, where each represented category corresponds to a component of experience - not to an entire holistic experience (Barsalou, 2003, p. 513). 
This claim leads to the suggestion that categorical knowledge for components of experience plays fundamental roles in cognitive systems by providing representational support for all cognitive processes, and that some kind of selectivity is occurring in the recall and utilisation of these simulations.

It follows, therefore, that as it is plausible and usual to relate professional competence with knowledge (Gruber, Harteis, \& Rehrl, 2008), it is appropriate to discuss the issue of intuition as component of professional performance from a cognitive perspective (i.e. as knowledge organisation and use). Certainly, although Gladwell (2005) may be a prominent author in the popular media, many other accounts also address intuition from a cognitive viewpoint. His account of intuitive decision making emphasises the significance of the first spontaneous response to an occupational task, as it is derived from implicit knowledge developed and enriched through years of experience. Without the need to balance alternatives and options, spontaneous decisions permit quick reactions to challenging situations. In this way, Gladwell's line of argumentation is consistent with the theory of fast and frugal heuristics (Gigerenzer \& Todd, 1998) that also claims the superiority of simple but viable solutions as appropriate (but eventually not optimal) responses to problem situations. Adopting a slightly different approach, Myers (2002) emphasises intuition as a thinking style that sits alongside, but is distinct from, the conscious, analytic one. Intuition, in his understanding, is the use of implicit knowledge that is not representable as conscious awareness. In this account, intuition is founded on tacit or implicit knowledge and is based in complex cognitive patterns, in ways described by Barsalou (2003) as simulations. The basic assumption of two parallel operating thinking modes also underlies the accounts of Davis and Davis (2003), Hogarth (2001), Klein (2003) and Sadler-Smith (2008), for example. These authors concur that the human mind functions in analytic or rational and heuristic or intuitive modes. Research on decision making seems to support this assumption, as recent accounts of judgments also position the intuitive and the rational thinking modes as two parallel and distinct thinking systems (Kahneman \& Frederick, 2002; Reyna, Lloyd, \& Brainerd, 2003; Sloman, 2002). These accounts share the precept with Hogarth (2001) and Myers (2002) that intuition utilises tacit knowledge and is not dependent on awareness and conscious thought. More to this, Bastick (2003) and Myers (2002) describe another cognitive facet of intuition: phenomenon of insight arising suddenly, especially in cases of longer, deliberate and unsuccessful thinking about a problem - and often after a period of incubation and rumination when thinking activities have been stopped. These findings are analogous to accounts of intuition as unconscious thinking (Dijksterhuis, 2004), thereby drawing on empirical evidence of experiments comparing the quality and outcomes of spontaneous versus conscious decision making (e.g. Dijksterhuis \& van Olden, 2006; Newell, Wong, Cheung, \& Rakow, 2009). Finally, and in a further distancing from the rational approaches, Bastic (2003) emphasises aspects of feelings and emotions in intuitive decision making. In different ways, the examples of intuition in action previewed at the beginning of this paper can be explained within these distinct 
accounts. Yet, a more defined, comprehensive and accessible account is now required to understand intuition further and advance consideration for its development.

Consequently, to advance this elaboration of intuition, those strands of theories that describe the process of information processing in more detail including the use of knowledge are now discussed. This is because they are of interest for educational interventions supporting the development of intuition. Therefore, the more psychologically oriented approaches of incubation, moments of insight and emotional influences on intuitive decision making are not emphasised in this discussion. This is not to suggest these accounts are irrelevant, but they are less relevant to advance considerations of supporting the development of intuition here.

\section{Two-systems / dual-modes theories of information processing}

A key assumption of cognitive accounts of intuition is that the mind's cognitive processes comprise two distinct modes of information processing that work in parallel. This assumption is labelled as twosystems/dual-modes theory. In adopting this line of argumentation and its applicability to considerations of being intuitive in work tasks, this section, first, discusses evidence supporting this precept, then two different empirical traditions are discussed to inform what constitutes the process of intuition: the first focusing on the perils of intuition and the second focusing on the potential of intuition.

\section{Evidence for the two-systems/dual-modes assumption}

In referring to the theories of working modes of the mind, accounts of decision making suggest it is enacted through two parallel and permanent operating information processing systems (Bruner, 1962; Hogarth, 2005; Kahneman \& Frederick, 2002; Sloman, 2002). For instance, Kahneman and Tversky (1972) in their early work investigated the phenomenon of people estimating things poorly in areas where they are usually considered to be competent. These authors subsequently developed the theory of two parallel systems of information processing (Sloman, 2002) which is now widely applied in research on decision making (e.g. Dane \& Pratt, 2007; Sadler-Smith \& Shefy, 2004). Although using different terminologies, in principle these authors concur that a mode of cognitive process operating deliberately, rationally and analytically engages with a mode working associatively, intuitively, and tacitly. Hammond (1993) even claimed that these two operation modes can be located on a continuum of consciousness. That is, the intuitive mode is on the unconscious end of the continuum and the rational mode on the conscious end, with distinction between these two modes being varied within this continuum. This conception suggests that intuitive decisions can be conscious (i.e. if somebody follows a gut feeling) and that rational decisions can be partly unconscious (e.g. if somebody follows a given order). 
An important and convincing reference for two-systems theories is found in optical deception. The theory "that two independent systems are at work depends critically on the fact that the perception and the knowledge are maintained simultaneously" (Sloman, 2002, p. 385). If observing pictures that indicate, incorrectly, lines of differing length only on the basis of three-dimensional illusions, subjects show tendencies to agree with the information that present the lines as being of similar length, yet also simultaneously try to identify reasons for the perception of differing lengths. Similar simultaneous beliefs or contradicting statements can be observed in arguing or concluding about probabilities (Tversky \& Kahneman, 1983). An early empirical study on intuition was conducted by Westcott (1968) who presented subjects with a bundle of problems that did not involve specific subject-matter knowledge, instead requiring mainly logical thinking. He investigated the amount of information subjects used for successful solutions and identified four categories of thinkers, which were grouped. One of these groups was defined as "intuitive thinkers" - and the correlations with psychometric features revealed a correlation with introversion within this group. Bargh and Chartrand (1999) offer a more thorough analysis of the intuitive system and identify three different processes generating seemingly spontaneous decisions: They propose intuition as an automatic effect of: i) perception on action, ii) automatic goal pursuit, and iii) a continual automatic evaluation of one's experience. These three processes are held to lead implicitly to an enrichment of experience that can be used in later situations without demanding awareness and recall to conscious decision making. Bargh (1982) investigated processing operations by applying acoustic stimuli and secured findings consistent with approaches claiming the existence of automatic (i.e. intuitive) and conscious control (i.e. aware) processes. Following similar approaches, Isenberg (1984) studied twelve executive managers and found that they do not follow precise goals or objectives when solving business challenges, but rely on a mix of intuition and rational analyses to work out pragmatic solutions.

Given these distinct orientations and starting points, it is perhaps not surprising that opinions differ across authors regarding mutual influences on human behaviour between intuitive and rational thinking modes. That is, are they dualities (i.e. interacting) rather than dualisms (i.e. separate)? In one line of interference, evidence suggests that the rational system can overrule the intuitive system in the case of retrospective reflecting of mistakes (Epstein, Lipson, Holstein, \& Huh, 1992). Conversely, Sloman (2002) proposes that in each rational decision, intuitive aspects appear because the intuitive system works associatively and, thus, operates more quickly than each subsequent rational consideration. Hence, intuitive traces always shape (even) perception and, through that, every decision independently.

Based on the two-systems theory, various accounts have been proposed claiming stable preferences of thinking or decision making. Several popular test instruments have been developed to indicate individuals' preferred thinking styles. For instance, Allinson and Hayes (1996) developed a questionnaire claimed to identify a general thinking style (Cognitive Style Index). Such an approach 
implies a general preference either for intuitive or for rational decision making. Other test inventories have been developed from similar starting points: Betsch's (2008) Preference for Intuition and Deliberation Scale (PID), Epstein, Pacini, Denes-Rej, and Heier's (1996) REI-questionnaire, Agor's AIM (Agor, 1984), and the well-known Myers Briggs Type Indicator (Briggs \& Myers, 1976). These instruments are widely used in research and personality diagnostics, but not for focused scientific investigations of intuition. Their authors' theoretical backgrounds are partly aligned with Jung's theory of holistic perception (Jung, 1923), as foreshadowed above, and address the tendency to trust intuitive perceptions rather than relying on rational analyses. Certainly, some empirical studies support the proposition that a capacity for intuitive decision making is positively correlated with high performance in problem-solving activities. In the domain of business management, for instance, Allinson, Chell, and Hayes (2000) compared the performances of senior and junior managers and demonstrated that success in business is not dependent on their experience alone, but is correlated with a preference for intuitive decision making.

As noted earlier, one of the crucial characteristics of the intuitive system of information processing (i.e. spontaneous reactions to a situation) is its relatedness to affections or dispositions (Slovic, Finucane, Peters, \& MacGregor, 2002). The intuitive system engages not only the rich basis of tacit knowledge, but also situational affect arising from the particular situation. Probably, the most influential account in this respect is Damasio's theory of somatic markers as "feelings generated from secondary emotions. These emotions and feelings have been connected, by individuals' learning, to predict outcomes of certain scenarios" (Damasio, 1994, p. 174). Somatic markers comprise biographical traces of emotional experiences that shape bases for affections or dispositions. Damasio conducted studies with patients with brain injuries and succeeded in demonstrating associations between the intuitive system and these somatic markers. He also demonstrates the importance of affective resources for decision making generally, as test subjects were unable to make any decisions even though they were able to explain rational considerations regarding the decision situation.

Hence, the intuitive system is held to permit individuals to make use of their tacit knowledge as well as dispositions (affect, value) in decision making. From the empirical evidence for the twosystems theory, the degree of separateness or interrelated qualities of these intuitive processes becomes a central explanatory issue. Yet, uncertainty about the relations between the intuitive and rational dimensions indicates that the form and potency of intuition still remain unclear. Consequently, the following section is used to identify the limits of intuition's potency and consider the bases of its potency. This is achieved through, firstly, elaborating situations when intuition fails and, secondly, those situations where intuition helps. 


\section{Failing intuition: The perils of biases and routines}

There is a body of research on heuristics and biases that identifies the negative aspects of intuitive decision making. In principle, experiments on heuristics and biases (Gilovich, Griffin, \& Kahneman, 2002) tend to support the existence of two processing systems, because all of them appear to prove mutual interference between these systems. Following from Brunswik (1956), who regarded intuitive estimations as either approximating correctness or being highly erroneous, a range of studies have illuminated the negative effect of intuitive decision making because of bias inherent in empirical designs. Peters, Hammond and Summers (1974), for instance, let subjects guess mathematical functions on the basis of various kinds of presented stimuli. In their study, intuitive estimations were more erroneous than analytical ones. Jacowitz and Kahneman (1995) let subjects estimate several quantities (e.g. height of Mt. Everest, numbers of bars in Berkeley, etc.) and presented an anchor (e.g. height of huge mountains, average number of bars in US cities) from which to measure influences on estimating responses. Interestingly, they identified stronger effects of those anchors that overtly overestimate the actual quantity, than those which underestimate the quantities. They suggest that intuitive judgements tend to be too optimistic and promote the danger of overestimation. Kahneman and Tversky (1973) initiated a series of experiments testing people's capacities to interpret and express the meaning of conditional probabilities (Bayesian probability). In these experiments, subjects frequently overestimated conditional probabilities presented in quantitative word tasks, even in fields of their professional expertise, for example, physicians overestimate the hit rate of positive AIDS or cancer test results (Eddy, 1982; Gigerenzer, 2002). However, Christensen-Szalinski and Beach (1982) emphasized the erroneous application of word problems in those tasks, because they could show that the experience of base-rates supports estimations close to Bayesian outcomes, even though subjects are unaware of the Bayesian formula. Then again, experiments involving choosing tasks between candidates found overestimation biases are not only necessarily related to beliefs about probability, but also plausibility (Sanbonmatsu, Posavac, \& Stasney, 1997). That is, subjects tended to neglect alternatives as soon as they experienced a situation that they viewed as being plausible.

Another source for biases in estimation performance is confidence. Fischoff, Slovic and Lichtenstein (1977) conducted experiments in which subjects had to estimate the validity of statements (e.g. "more people die by homicide than suicide") - statements where the subjects do not have complete information - and coevally had to declare their confidence regarding their judgment. They found that false estimations often came along with high confidence. An explanation of this relationship was presented and empirically supported by Gigerenzer, Hoffrage and Kleinbölting (1991) who developed the theory of probabilistic mental models. In contrast to these findings, a study in the professional domain of clinical assessment revealed that the subjective confidence of clinicians' predictions about patients' potential for violence was "an important moderator of the predictive validity of those evaluations" (McNiel, Sandberg, \& Binder, 1998, p. 664). These findings are also 
consistent with those from research on the superstition of a "hot hand" or streak shooting success in sporting activities. Here, subjects tended to overestimate even short sequences of success and failing for predictions on the success of following free throws in basketball. However, in reality, the previous sequences only influence the predictions, but not the players' performance (Gilovich, Vallone, \& Tversky, 1985). This finding suggests that there are various phenomena of overestimation, even in areas where people have knowledge about the area in which they are making judgments. These are all examples of bad outcomes of spontaneous intuitive judgments.

Besides the kind of biases described so far, another negative effect of intuitive decision making arises from failing routines in the widest sense. Slovic (2001) provides a symptomatic example of an affective fallacy when investigating young smokers who balance the pleasure they gain from smoking against the factual knowledge of dangers of smoking which will affect them in the future. In this study, the great majority of smokers expected to stop smoking soon, independently of how long or how strongly they habitually smoke. Slovic (2001) explains that smokers, even though recognising and understanding the consequences of smoking, actually enjoy smoking. A tragic example of applying routines of consideration is provided by Klein's (1998) analysis of the launch of a missile against a civil Iran-Air aircraft in July 1988. The captain of a US warship mentally simulated various interpretations of a set of partly ambiguous and conflicting information and came - under extreme time pressure - to the conclusion that the ship was at risk of being attacked and subsequently launched an anti-aircraft missile at the civilian aircraft with huge loss of life. Thus, an expert process of decision making ended in a drastically incorrect decision with tragic consequences. Although, it could be emphasised that the warship captain's intuitive conclusions could have been shaped by a priority to save the vessel and lives of the crew of which he was in charge.

So, there is no guarantee that what is described as intuitive decision making will be effective, and on a range of measures and circumstances it can be seen as being erroneous and, in some cases, absolutely wrong. However, in moving away from tasks requiring simple factual relations and recall, and engaging with more demanding tasks, the decision making inevitably becomes more difficult and the quality of the outcomes more subject to judgement. For instance, it would be surprising for smokers to rationalise their behaviour even given time for retrospection. Equally, it could be claimed that the ship's captain secured the safety of his ship and crew, which stand as the key premise for his decision making, despite the huge cost in civilian lives. So, it now seems timely to consider the kinds of decision making in which intuition is reported as being successful.

\section{Successful intuition}

The majority of investigations conducted on the positive effects of intuition focus on spontaneous heuristics. That is, the almost instantaneous application of problem-solving procedures that, while not guaranteeing success, are likely to secure effective outcomes. Much of this research is premised on the 
assumptions of the two-systems theory as it implies and compares the options of rational and deliberate problem solving against intuitive and spontaneous solutions. The starting point of authors arguing for spontaneous heuristics is the complexity of problems faced in real-world situations, in general, and professional working life, in particular. Overall, full rationality in decision making could require unlimited cognitive resources, yet human perception and processing is quite limited (Selten, 2002). Moreover, most decisions in working life have to be made under time constraints or with restricted or incomplete information, requiring the decision makers to elaborate what they know and generate the most appropriate responses under those conditions. Under such conditions, assumptions about wholly rational, logical inference as the key principle for decision making are inappropriate and unrealistic (Gigerenzer \& Goldstein, 1996). Simon (1957) introduced the idea of bounded rationality as model for decision making under such constraints and proposed the principle of "satisfycing" in contrast to optimisation as the idea of rationality. Satisfycing describes a blend of satisfying and sufficient means by which to come to an appropriate solution under conditions of constraints. The appropriateness of a solution arises from goal variables that have to be generated, and when this point is reached, the search process is curtailed.

Another perspective is that of fast and frugal heuristics, as mentioned earlier. The premise for these heuristics is that human decision-making behaviour can be represented as a frugal model which describes a search rule, a stopping rule and a rule for choosing (Gigerenzer \& Goldstein, 1996). The search rule describes the logic of discharging available options (e.g. increasing prices when comparing sales offers); stopping the execution of that rule addresses characteristics of the option which sufficiently discriminate alternatives. Rules for choosing include considerations underlying the processes of choice. Several of those fast and frugal heuristics have been identified: A "take the best" heuristic (Gigerenzer \& Goldstein, 1999) describes a reasonable decision strategy which refers to the stopping and choosing rule for considerations not necessarily connected to decision making (e.g. recognition of relevant objects). In the domain of handball, Johnson and Raab (2003) identified that "take the first" heuristic - which means that one should trust the first idea - can generate good results. "As if" heuristics describe simple rules that lead to the same result as complex mathematical equitation, for example, the catching of a baseball can be described by a simple rule to keep the viewangle to the ball constant, but also by a complex physical equation (Shaffer \& McBeath, 2002). As these subjects do not necessarily have to be aware of those heuristics and do not balance alternatives when applying those heuristics, those processes meet the definition of intuition given at the beginning of this paper. That is, the capability to act or decide appropriately without deliberately and consciously balancing alternatives, and without following a certain rule or routine, and, possibly, without awareness (Harteis, Koch, \& Morgenthaler, 2008; Hogarth, 2005; Kahneman \& Klein, 2009). However, this account of intuition contains a tricky problem. It is a crucial and basic question whether it is acceptable to describe human behaviour with a (predictive) cognitive model when there is an 
external attribution which has no verifiable correlate with subjects' internal cognitive processes. It is conceivable that the detection of a fast and frugal heuristic describes just an abbreviation in a cognitive pattern that influences intuitive decision making. At least, this is how the protagonists of fast and frugal heuristics construct their theoretical concept, as they concede that these heuristics "simulate people" (Gigerenzer \& Goldstein, 1996, p. 655). On the other hand, there is no doubt that certain problems demand such an investigative strategy. This was evident when Dhami and Ayton (2001) found that for 27 magistrates the administration of justice sometimes depends on individual biographies: Magistrates' bail decisions can be modelled in a frugal heuristic based on whether or not a suspect had previous contact with court. However, it remains unclear if these subjects were aware of that heuristic (they probably never would confess). Thus, doubts arise whether fast and frugal heuristics are really intuitive ones. It might be more probable that they are just applications of a heuristic which proved to be successful.

\section{Cognitive accounts in summary}

The two-systems theory proposes two parallel operating systems of information processing as an inherent feature of human cognition. As the discussion revealed, intuitive decision making can be either deficient or beneficial. Thus, theoretical approaches of intuitive decision making referring solely to the two-systems theory are not wholly satisfactory for explaining extraordinary performances as described in earlier cases. Kahneman and Klein (2009) deal with the characteristics of the different research perspectives on intuitive decision making. They attribute empirical evidence for the limitations of intuition primarily to the researchers' interest on either experts' errors or experts' extraordinary performances. In the context of professional activities, the interest is on explanations about how best to identify the potential of intuition and to support individuals in making use of intuitive systems and avoiding their shortcomings.

Other viewpoints also advise caution in adopting the theory of fast and frugal heuristics as a complete explanation of intuition in professional work performance. For instance, in a study comparing the decisions of stock market professionals with those of housewives, Borges, Goldstein, Ortmann and Gigerenzer (1999) claimed that even ignorance-based frugal heuristics can perform better than more sophisticated kinds. However, the researchers organised an artificial competition which has nothing to do with professional competition because ignorance should not be a characteristic of professionalism. In addition, the experiment fails to reveal the extent to which either the housewives or the experts made decisions intuitively. Another point is that relying on one (frugal) heuristic is not a characteristic feature of professional behaviour. In domains where fast and frugal heuristic have been tested, expectations regarding professional performance indicate flexible responses (for sport: Ward, Hodges, Williams, \& Starkes, 2004; for investment: Agor, 1986a). It is unlikely that 
the repeated application of the same heuristic would continue to be a successful strategy in domains of professional work life because of the changing requirements of effective problem solving. A third disadvantage of fast and frugal heuristics is the limited information base of their heuristics and how these are learnt. However, some authors (e.g. Gigerenzer \& Gaissmaier, 2011) refer to Simon's statement that "intuition is nothing more and nothing less than recognition" (Simon, 1982, p. 155) and, in doing so, imply that intuition is dependent on memory, yet mostly nothing about the subjects' cognitive background is reported in these accounts. However, particularly when there is an educational intent, an account is needed where knowledge, competencies and capacities are taken as prerequisites for intuition, in order to be able to develop instructional bases for developing intuitive decision making. Theories on expertise provide a firmer set of premises for developing an educational account of intuition, and they are aligned to the differences between experienced and inexperienced persons introduced at the beginning of this article.

\section{Intuition as component of expertise}

Accounts of expertise usually describe the development of individuals' knowledge structures during the development phases from novice to experts. This approach dates from studies on chess that were used to understand the role of memory in extraordinary performances of perception and recognition (Chase \& Simon, 1973a/b), but which were subsequently replicated across a range of occupational fields. Findings from these studies suggest that decision-making behaviour does not always completely follow rationality (Simon, 1955) and that experts recognise patterns in complex arrangements that enable them to respond spontaneously in ways that novices could not and possibly would not. On these bases, the idea of intuition as recognition arose and was established (de Groot, 1986) on the premise of knowledge that had been learnt over time and was, in part, rendered beyond immediate consciousness. These lines of conceptual development are aligned with the accounts of fast and frugal heuristics as discussed above. For instance, from such foundations Dreyfus and Dreyfus (1986) developed a five-step model for the development of expertise, in which the highest level of expertise is the level of intuitive action which does not demand the engagement of conscious effort, demanding thought or reflection, and even does eventually not demand awareness by the expert. Their concept of expertise, however, differs markedly from the fast and frugal heuristics account because in their model, intuition uses the rich knowledge of which people are not or no longer aware. Instead, this knowledge is developed over time by experience and eventually by engagement within a professional domain of occupational activities. A well-known example they quote refers to chicken sexers who work at chicken farms and distinguish male and female chicken at the age of few days on a basis in which rational descriptions seem to fail. This profession was imported from Japan, where chicken sexing has a long tradition and an apprenticeship that focuses on a long process of implicit learning by doing and enculturation, and refers to the far East Zen philosophy (Lunn, 1948). Qualified chicken 
sexers can identify the gender of 2,000 chicks in one hour with a level of 98 percent accuracy (Biederman \& Shiffar, 1987). However, these workers are unable to report their decision ratio; they are just doing it (Schroeder, 1933) intuitively (Dreyfus \& Dreyfus, 1986). This suggests that the basis of the recognition to which Simon (1982) refers is rendered unconscious as with so many other proceduralised capacities (e.g. driving a car). However, not all of the instances of effective intuitive performance discussed earlier are aligned to this kind of capacity (i.e. practiced and proceduralised capacities). For instance, neither the emergency surgery workers nor the pilot Sullenberger had been exposed to multiple instances of the experiences for which they intuitively developed effective responses. So, it is necessary to go beyond accounts of highly practised procedures that can be applied almost automatically (i.e. through automaticity (Anderson 1982)) to understand and develop what constitutes intuition.

Eraut (1994) reviewed research on professional expertise to identify how it might best be learnt. He claims that experts' structuring of explicable (i.e. declarative) knowledge accounts for only one (important) aspect of professional performance. He notes that intuition is an important supplement which is not likely to be declared or is even declarative. He defines intuition as

... not only pattern recognition but also rapid responses to developing situations ... based on the tacit application of tacit rules. These rules may not be explicit or capable of reasoned justification, but their distinctive feature is that of being tacit at the moment of use (Eraut, 2000, p. 127).

Intuition in this account may support the execution of performing a fast heuristic, but it is far from frugal. Instead, it is a compilation of complex knowledge patterns, developed by implicit learning during processes of engagement with the professional practice (Reber, 1993) or by automatisation and development of routines (Eraut, 1994), through processes of proceduralisation that Anderson (1982) describes in detail. The problem arising here, however, is that routines and automatisms are not necessarily appropriate for complex problem-solving cases, especially if they are new to individuals, thereby making them not actionable by standard (specifically learnt) routines. Researchers of expertise, thus, developed the idea that critical reflection of experiences is a crucial prerequisite for extraordinary high performances - best realised by an immersion into a community of experts in ways that cultivates exchanges and reviews of experiences amongst peers (Berliner, 2001; Gruber, Harteis \& Rehrl, 2008). Perhaps it was also these kinds of experiences assisted the captain of the plane crippled by geese flying into its engines make intuitive decisions, because these incidents had been discussed in that community as a possibility. Certainly, there are at least three distinct theoretical concepts available explaining the cognitive processes of reflecting practical experiences. In his $\mathrm{ACT}^{*}$ model, Anderson (1982) proposes the process of skill acquisition in three phases of: i) development of declarative knowledge, ii) compilation into procedural knowledge and iii) tuning of this procedural 
knowledge on the basis of practical experiences of failing and success. This account assists understanding how highly practised procedures can become compiled and proceduralised and reduced in cognitive demands in ways that render them into unconscious forms, because this process aims to reduce demands on working memory. However, as noted, an account of intuition emphasising automatic unconscious responses is probably one that cannot account for the pilot Sullenberger's response, because he had not had experienced and rehearsed this activity. Similarly, Kolodner's (1983) concept of dynamic memory considers similar processes by claiming that the reflection of experiences results in either a confirmation of procedures and routines in cases of success or in a modification of routines in cases of failings. Klein (2003) also assumes that experts develop mental models which explain their extraordinary capabilities. These mental models develop not only by practical experiences, but also in mental simulations of action scripts. That is, there are more general, but likely also domain-specific heuristics, that can be enacted almost unthinkingly, as well as more specific forms of procedures that can be enacted without requiring immediate conscious thought. Indeed, these processes are learnt and their enactment is premised on them not requiring recourse to conscious memory. Exemplarily empirical studies revealed evidence for this understanding of intuitive expertise: In a forecast-experiment of stock market prices experts' intuitive forecasts of aggregated stock values (i.e. DAX as German stock index and the exchange rate between Euro and US\$) were significantly better than forecasts resulting from a deliberate information collection (Harteis, \& Gruber, 2008). In a simulation study, experts in emergency medicine performed better than semi-experts and novices when intuitive problem solving was necessary (Harteis et al., 2012).

As a component of expertise, intuition appears to make three cognitive contributions to effective decision making in crucial and complex problem situations: First, within the particular personal domain of activities, intuition helps to compensate for the limitations of bounded rationality because experts are capable of recognising crucial patterns in complex and confusing scenarios. Because they can quickly identify crucial points where interventions are necessary, they can act quickly and perform better than novices who are unable to identify these crucial elements. Second, experts possess a rich variety of procedures that enable them to solve routine problems spontaneously and with apparently limited cognitive effort, because they can use their demand on conscious memory effectively and direct it towards aspects of the task requiring such engagement. This strategic use of decision-making capacities enables them to perceive more details of situations because the familiar aspects of tasks do not make demands upon their conscious thinking and acting. However, experts usually also know when routines do not work or are not working though their monitoring of what they do, including expectations of how they expect the task will progress. An example for this is Klein's (2003) episode where the commander calls his firefighters back from a house as he quickly concluded that the orthodox approach to extinguishing a fire will fail in this instance. The basis for this intuition is - and this is the third cognitive aspect of intuition - that intuition makes use of knowledge resources 
of which people are aware, but also utilises rich sources of the tacit knowledge experts developed across their lives. The somatic markers as advanced by Damasio (1994) can be considered as a specific kind of tacit knowledge. Intuition can be considered as a capability for permitting this emotionally based tacit knowledge (Immordino-Young \& Damasio, 2007). In professional domains, where rationality is the guiding principle of proceeding with action, the likely tendency is to attempt to ignore these kinds of non-declarative knowledge.

In summary, intuition is an important component of expertise as long as experts are aware of the danger of routine-blindness and if they redress this shortcoming through being introspective about their practice experiences and use their critical, strategic faculties optimally - at best by engaging with a community of experts. This perspective implies that intuition is - as expertise - a domain-specific capability that cannot be generalised because intuition differs as a stable characteristic of individuals. Indeed, Kahneman and Klein (2009) explain the phenomena of experts tending to be overconfident about their own judgments as a product of their trying to fulfil expectations of their performance once being categorised as experts, even in areas where they actually lack of expertise. Hence, expertise alone does not necessarily make for effective intuitive action. Experts have to be aware of possible biases (as described above) and have to engage their knowledge effectively and utilise their strategic capacities including enacting executive roles when advancing intuitive actions sourced in their existing knowledge and, from this, the capacity for appropriate intuitive decision making.

\section{Discussion: promoting the development of intuition}

The sections above explored the role of intuition for intense and urgent work performance requirements by focusing on cognitive theories of information processing and knowledge development. It became obvious that intuitive moments of performing may be advantageous as well as disadvantageous because tacit knowledge and knowing can be a strong basis for acting. However, intuitions may also compromise the analysis of challenging situations if spontaneous reactions prove to be inappropriate. The expertise perspective on intuition introduced a clear emphasis and reliance on human learning and development. With regard to intuition, the development of expertise implies learning to utilise the power of intuition and to avoid its perils. Therefore, it has a learning dimension, as intuition is founded on knowledge that is developed through individuals' explicit and implicit learning processes. Thus, the development of expertise offers an educational basis for promoting the development of effective intuitive acts. Hence, the question arises how best to support the development of capabilities to utilise intuition effectively and fruitfully.

A range of researchers in the field of expertise have investigated learning processes in professional domains and at workplaces, although not all explicitly address intuition as a component of professional competence (for an overview: Dochy, Gijbels, Segers, \& van den Bossche, 2011; 
Tynjälä, 2013). However, most address issues of implicit learning and tacit knowledge and, thus, they (implicitly) consider all prerequisites for the development of intuition. A common aspect of promoting this kind of learning refers to the importance of authentic learning environments - as in workplaces. A key quality of these experiences is their capacity to make accessible to learners the ability to grasp implicit rules of social practices that are crucial to professional practice (Billett, 2006; Dochy et al., 2011, Illeris, 2011). This idea follows Eraut's argument that professional learning occurs mostly outside of educational or instructional interludes at workplaces, but is influenced by experiences in those settings as well, including those that learners had earlier (Eraut, 2000). Within workplace setting, individuals are afforded opportunities to progressively participate in shared practices which make accessible the routines and heuristics of more experienced co-workers. Eraut emphasises the importance of tacit knowledge and intuition for high professional performance - and he claims everyday learning experiences in the circumstances of professional practice are essential for experiencing, developing, refining, and honing what has been learnt earlier and generating tacit knowledge, routines and heuristics that are shaping professional practice in particular workplace settings. Yet, to be effective, these processes require more expert co-workers who can furnish models for performance, guide that learning directly or indirectly and otherwise support that learning, including by providing feedback to learners on their work performance (Billett, 2000). Yet, in work environments in which learning efforts compete against demands of productivity, it may be difficult to establish a learning culture that provides opportunities for necessary processes of guidance, feedback, and learning (Evans, Hodkinson, Rainbird, \& Unwin, 2006; Harteis, Bauer, \& Heid, 2012). Hence, a potentially crucial prerequisite for the development of intuition the implementation of working practices that provide space for learning experiences, as the development of intuition - as this article explored - arises from the outcomes of experiential learning.

Moreover, beyond guidance in the workplace are also individuals' contributions. Just as earlier learning experiences in educational settings are interpreted and shaped differently by individual influences, so too is professional learning through work. Indeed, Sternberg et al. (2000) link intelligence as an individual factor with sharing of experience and practice as a social factor for describing the development of intuitive capacities as "practical intelligence". In a similar way, Salmela and Moraes (2003) describe the development of expertise in professional sport by pointing out that, besides individual talent and will, various social frameworks such as coaches, teams, families and society influence the development or absence of successful career. A systematic discussion of the role of individual and social influences for the development of professional competence can be found, for example, in the work of Eteläpelto and Collin (2004) and Billett (2006). They propose that both aspects (i.e. individual and social influences) are strongly interrelated in learning for both highly specific procedures that can be applied without recourse to conscious thought and also the kinds of goals and states that emanate from particular social settings. However, there is still a lack of empirical 
studies investigating the interrelations between individual and social contributions to learning and the effects of these interrelations for learning outcomes in general, and for the development of intuitive expertise in particular. The recently published handbook of intuition research (Sinclair, 2011) provides two exemplary approaches to supporting the development of intuition, but one is solely focused on individual aspects of learning (Tomasino, 2011); the other one discusses curricular opportunities for developing intuitive expertise (Burke \& Sadler-Smith, 2011). However, there is again a rather separated approach to understanding learning professional capacities. Although there have been some detailed studies and empirical evidence about how these interrelations between individual and social influences affect learning processes and outcomes (e.g. Billett, 2003), this still remains to be tested in larger studies.

In all, there is still a need for further development in methodology for investigating intuition. Some empirical studies in the area of professional domains apply instruments measuring general preferences (e.g. Cognitive Style Index, Myer-Briggs-Type Indicator). Such approaches imply general preferences which somehow contradict the main insight of research on expertise - that knowledge and capabilities are inevitably domain-specific qualities. Additionally, it remains unclear if and how far general preferences actually guide behaviour in real work situations. Other studies aimed at implementing action conditions which foster either rational or intuitive decision making. In these studies, problems occurred that were quite distinct in terms of either intuitive and rational acting. Finally, studies that used 'think aloud' protocols to make accessible the knowledge basis of acting always are limited by the fact that they generate accounts that may or may not reflect unconscious mental processes. The point is you can never be sure. So far, each attempt to empirically investigate intuition has to struggle with specific limitations such as these. There is still potential to develop methodology to secure richer empirical insights about the development of intuition and its scope of applicability. The recent developments using brain scans may be helpful in the future. Certainly, it seems that the development of intuitive expertise requires going beyond accounts of rehearsal and practice as in proceduralisation, to engage a broader set of perspectives and accounts that can be used in circumstances which are not rehearsed. The pilot Sullenberger knew he needed to land the plane and the fact that landing on water is something that is mentioned by every flight crew on every flight indicates that it was a possibility in this field, and, when faced with the available options, was the most likely survivable option. It was then that other skills associated with landing a plane in restricted circumstances came into play. All of this emphasises that intuitive expertise is likely to be associated with the development of domains of knowledge, yet also capacities and facilities that permit openness and flexibility in their execution. In many ways, when dealing with intuitive expertise within professional roles, having knowledge of the scope of possibilities is at least as important as routinized and rehearsed procedures. 


\section{References}

Abernathy, C. M. \& Hamm, R. M. (1995). Surgical intuition. What it is and how to get it. Philadelphia: Hanley \& Belfus.

Agor, W. H. (1984). Intuitive management. Englewood Cliffs: Prentice-Hall.

Agor, W. H. (1986a). The logic of intuitive decision making: A research based approach for top management. Westport: Quorum Books.

Agor, W. H. (1986b). The logic of intuition: How top executives make important decisions. Organizational Dynamics, 14, 5-18.

Allinson, C. W., Chell, E., \& Hayes, J. (2000). Intuition and entrepreneurial behaviour. European Journal of Work and Organizational Psychology, 9, 31-43.

Allinson, C., \& Hayes, J. (1996). The Cognitive Style Index: A measure of intuition-analysis for organisational research. Journal of Management Studies, 33, 119-135.

Andersen, J. A. (2000). Intuition in managers. Are intuitive managers more effective? Journal of Managerial Psychology, 15, 46-67.

Anderson, J. R. (1982). Acquisition of cognitive skill. Psychological Review, 89, 369-406.

Asvoll, H. (2012). Perspectives on reflection and intuition in a teacher practice: a comparison and possible integration of the cognitive constructivist and the Dreyfusian intuitive perspectives. Reflective Practice, 6, 789-804.

Atkinson, T., \& Claxton, G. (Eds.). (2000). The intuitive practitioner. On the value of not always knowing what one is doing. Maidenhead: Open University Press.

Bargh, J. A. (1982). Attention and automaticity in the processing of self-relevant information. Journal of Personality and Social Psychology, 43, 425-436.

Bargh, J. A., \& Chartrand, T. L. (1999). The unbearable automaticity of being. American Psychologist, 54, 462-479.

Barsalou, L. W. (2003). Situated simulation in human conceptual system. Language and Cognitive Processes, 18, 513-562.

Bastick, T. (2003). Intuition. Evaluating the construct and its impact on creative thinking. Kingston: Stoneman \& Lang.

Beach, K. (1993). Becoming a bartender: The role of external memory cues in a work-directed educational activity. Applied Cognitive Psychology, 7(3), 191-204.

Beck, N. (1995). Shifting gears ... thriving in the new economy. Toronto: Harpercollins.

Berliner, D. C. (2001). Berliner, D. C. (2001). Learning about and learning from expert teachers. International Journal of Educational Research, 35, 463-482.

Betsch, C. (2008). Chronic preferences for intuition and deliberation in decision making: Lessons learned about intuition from an individual differences approach. In $\mathrm{H}$. Plessner, C. Betsch, \& T. Betsch (Eds.), Intuition in judgment and decision making (pp. 231-248). New York: Lawrence Erlbaum.

Biederman, I., \& Shiffar, M. M. (1987). Sexing day-old chicks. Journal of Experimental Psychology: Learning, Memory, and Cognition, 13, 640-645.

Billett, S. (1993). Authenticity and a culture of workpractice. Australian and New Zealand Journal of Vocational Education Research, 2(1), 1-29.

Billett, S. (2000). Guided learning at work. Journal of Workplace learning, 12(7), 272-285.

Billett, S. (2003). Sociogeneses, activity and ontogeny. Culture and Psychology, 9(2), 133-169.

Billett, S. (2006). Work, change and workers. Dordrecht: Springer.

Borges, B., Goldstein, D. G., Ortmann, A., \& Gigerenzer, G. (1999). Can ignorance beat the stockmarket? Name recognition as a heuristic for investing. In G. Gigerenzer, P. M. Todd \& the ABC Research Group (Eds.), Simple heuristics that make us smart (pp. 59-72). New York: Oxford University Press.

Briggs, K. C., \& Myers, I. B. (1976). The Myers Briggs type indicator. Palo Alto: Consulting Psychologists Press.

Bruner, J. (1962). On knowing. Cambridge: Harvard University Press.

Brunswik, E. (1956). Perceptions and the representative design of experiments. Berkeley: University of California Press. 
Burke, L. A., \& Sadler-Smith, E. (2011). Integrating intuition into higher education: a perspective from business management. In M. Sinclair (Ed.), Handbook of intuition research (pp. 237-246). Cheltenham: Edward Elgar.

Chase, W. G., \& Simon, H. A. (1973a). The mind's eye in chess. In W. G. Chase (Ed.), Visual information processing (pp. 215-281). New York: Academic Press.

Chase, W. G., \& Simon, H. A. (1973b). Perception in chess. Cognitive Psychology, 4, 55-81.

Christensen-Szalinski, J. J. J., \& Beach, L R. (1982). Experience and the base-rate fallacy. Organizational Behavior and Human Performance, 29, 270-278.

Chudnoff, E. (2013). Intuitive knowledge. Philosophical Studies, 162, 359-378.

Crandall, B., \& Getchell-Reiter, K. (1993). Critical Decision Method: A technique for eliciting concrete assessment indicators from the intuition of NICU nurses. Advances in Nursing Sciences, 16(1), 42-51.

Damasio, A. (1994). Descarte's error. London: Vintage Books.

Damasio, A. (2012). Self comes to mind: Constructing the conscious brain. London: Vintage.

Dane, E., \& Pratt, M. G. (2007). Exploring intuition and its role in managerial decision making. Academy of Management Review, 32(1), 33-54.

Davis, S. H., \& Davis, P. B. (2003). The intuitive dimensions of administrative decision making. Oxford: Scarecrow.

de Groot, A. D. (1986). Intuition in chess. International Computer Chess Association Journal, 9, 67-75.

Dhami, M. K., \& Ayton, P. (2001). Bailing and jailing the fast and frugal way. Journal of Behavioral Decision Making, 14, 141-168.

Dijksterhuis, A. (2004). Think different: The merits of unconscious thought in preference development and decision making. Journal of Personality nad Social Psychology, 87, 586-598.

Dijksterhuis, A., \& van Olden, Z. (2006). On the benefits of thinking unconsciously: Unconscious thought can increase post-choice satisfaction. Journal of Experimental Social Psychology, 42, 627-631.

Dochy, F., Gijbels, D., Segers, M., \& van den Bossche, P. (2011). Theories of learning for the workplace. London: Routledge.

Dreyfus, H. L., \& Dreyfus, S. E. (1986). Mind over machine. The power of human intuition and expertise in the era of the computer. New York: The Free Press.

Eddy, D. M. (1982). Probabilistic reasoning in clinical medicine: problems and opportunities. In D. Kahneman, P. Slovic, \& A. Tversky (Eds.), Judgment under uncertainty: Heuristics and biases (pp.249-267). Cambridge: Cambridge University Press.

Eisenkraft, N. (2013). Accurate by way of aggregation. Should you trust your intuition-based first impressions? Journal of Experimental Social Psychology, 49, 277-279.

Epstein, S., Lipson, A., Holstein, C., \& Huh, E. (1992). Irrational reactions to negative outcomes: Evidence for two conceptual systems. Journal of Personality and Social Psychology, 62, 328-339.

Epstein, S., Pacini, R., Denes-Rej, V., \& Heier, H. (1996). Individual differences in intuitiveexperiental and analytical-rational thinking styles. Journal of Personality and Social Psychology, 71, 390-405

Eraut, M. (1994). Developing professional knowledge and competence. London: Routledge Falmer.

Eraut, M. (2000). Non-formal learning and tacit knowledge in professional work. British Journal of Educational Psychology, 70, 113-136.

Eteläpelto, A., \& Collin, K. (2004). From individual cognition to communities of practice. In H. P. A. Boshuizen, R. Bromme, \& H. Gruber (Eds.), Professional learning: Gaps and transitions on the way from novice to expert (pp. 231-250). Dordrecht: Kluwer.

Evans, K., Hodkinson, P., Rainbird, H., \& Unwin, L. (2006). Improving workplace learning. London: Routledge. 
Fischhoff, B. (2002). Heuristics and biases in application. In T. Gilovich, D. Griffin, \& D. Kahneman (Eds.), Heuristics and biases. The psychology of intuitive judgment (pp. 730-748). Cambridge: Cambridge University Press.

Fischhoff, B., Slovic, P., \& Lichtenstein, S. (1977). Knowing with certainty: The appropriateness of extreme confidence. Journal of Experimental Psychology: Human Perception and Performance, 3, 552-564.

Frank, M. J., O'Reilly, R. C., \& Curran, T. (2006). When memory fails, intuition reigns. Psychological Science, 17, 700-707.

Gigerenzer, G. (2002). Reckoning with risk. Learning to live with uncertainty. London: Penguin Books.

Gigerenzer, G. (2007). Gut feelings. The intelligence of the unconscious and the power of intuition. New York: Viking.

Gigerenzer, G., \& Gaissmaier, W. (2011). Heuristic decision making. Annual Review of Psychology, 62, 451-482.

Gigerenzer, G., \& Goldstein, D. G. (1996). Reasoning the fast and frugal way: Models of bounded rationality. Psychological Review, 103, 650-669.

Gigerenzer, G., \& Goldstein, D. G. (1999). Betting on one good reason. The take the best heuristic. In Gigerenzer, P. M. Todd and the ABC Research Group (Eds.), Simple heuristics that make us smart (pp. 75-95). Oxford: Oxford University Press.

Gigerenzer, G., Hoffrage, U., \& Kleinbölting, (1991). Probabilistic mental models: A Brunswikian theory of confidence. Psychological Review, 98, 506-528.

Gigerenzer, G., \& Todd, P. M. (1998). Fast and frugal heuristics: The adaptive toolbox. In G. Gigerenzer, P. M. Todd and the ABC Research Group (Eds.), Simple heuristics that make us smart (pp. 3-34). Oxford: Oxford University Press.

Gilovich, T., Griffin, D., \& Kahneman, D. (Eds.). (2002). Heuristics and biases. The psychology of intuitive judgement. Cambridge: Cambridge University Press.

Gilovich, T., Vallone, R., \& Tversky, A. (1985). The hot hand in basketball: On the misperception of random sequences. Cognitive Psychology, 17, 295-314.

Gladwell, M. (1999). The physical genius. The New York Times, 8/2/99, 57-66.

Gladwell, M. (2005). Blink. The power of thinking without thinking. New York: Little, Brown \& Company.

Glastra, F. J., Hake, B. J., \& Schedler, P. E. (2004). Lifelong learning as transitional learning. Adult Education Quarterly: A Journal of Research and Theory, 54, 291-307.

Gruber, H., Harteis, C., \& Rehrl, M. (2008). Vocational and professional learning: Skill formation between formal and situated learning. In K. U. Mayer \& H. Solga (Eds.), Skill formation. Interdisciplinary and cross-natural perspectives (pp. 207-229). Cambridge: Cambridge University Press.

Hall, K. (2002). Reviewing intuitive decision-making and uncertainty: the implications for medical education. Medical Education, 36, 216-224.

Hammond, K.-R. (1993). Natural decision making from a Brunswikian viewpoint. In G. A. Klein, J. Orasanu, R. Calderwood, \& C. E. Zsambok (Eds.), Decision making in action: Models and methods (pp. 205-227). Westport, CT, US: Ablex Publishing.

Harteis, C., Bauer, J., \& Heid, H. (2012). Research on human fallibility and learning from errors at work: Challenges for theory, research, and practice. In J. Bauer \& C. Harteis (Eds.), Human fallibility. The ambiguity of errors for work and learning (pp.255-265). Dordrecht: Springer.

Harteis, C., \& Gruber, H. (2008). Intuition and professional competence: Intuitive versus rational forecasting of the stock market. Vocations and Learning. Studies in Vocational and Professional Education, 1, 71-85.

Harteis, C., Koch, T., \& Morgenthaler, B. (2008). How intuition contributes to high performance: An educational perspective. US-China Education Review, 5(1), 68-80.

Harteis, C., Morgenthaler, B., Kugler, C., Ittner, K.-P., Roth, G., \& Graf, B. (2012). Professional competence and intuitive decision making: A simulation study in the 
domain of emergency medicine. Vocations and Learning. Studies in Vocational and Professional Education, 5, 131-147.

Hogarth, R. M. (2001). Educating intuition. Chicago: The Chicago University Press.

Hogarth, R. M. (2005). Deciding analytically or trusting your intuition? The advantages and disadvantages of analytic and intuitive thought. In T. Betsch \& S. Haberstroh (Eds.), The routines of decision making (pp. 67-82). Mahwah: Lawrence Erlbaum.

Illeris, K. (2011). Workplaces and learning. In M. Malloch, L. Cairns, K. Evans \& B. O'Connor (Eds.), The SAGE Handbook of Workplace Learning (pp.32-45). London: SAGE.

Immordino-Young, M. H., \& Damasio, A. (2007). We feel, therefore we learn: The relevance of affective and social neuroscience to education. Mind, Brain, and Education, 1, 3-10.

Isenberg, D. J. (1984). How senior managers think. Harvard Business Review, 62(6), 81-90.

Jacowitz, K. E., \& Kahneman, D. (1995). Measures of anchoring in estimation tasks. Personality and Social Psychology Bulletin, 21, 1161-1166.

Janelle, C. M., \& Hillman, C. H. (2003). Expert performance in sport: Current perspectives and critical issues. In J. L. Starkes \& K. A. Ericsson (Eds.), Expert performance in sports: Advances in research on sport expertise (pp. 19-47). Champaign: Human Kinetics.

Johnson, J. G., \& Raab, M. (2003). Take The First: Option-generation and resulting choices. Organizational Behavior and Human Decision Processes, 91, 215-229.

Jung, C. G. (1923). Psychological types or the psychology of individuation. London: Kegan \& Co

Kahneman, D., \& Frederick, S. (2002). Representativeness revisited: Attribute substitution in intuitive judgment. In T. Gilovich, D. Griffin, \& D. Kahneman (Eds.), Heuristic and biases. The psychology of intuitive judgment (pp. 49-81). Cambridge: Cambridge University Press.

Kahneman, D., \& Klein, G. (2009). Conditions for intuitive expertise. A failure to disagree. American Psychologist, 64, 515-526.

Kahneman, D., \& Tversky, A. (1972). Subjective probability. A judgment of representativeness. Cognitive Psychology, 3, 430-454.

Kahneman, D., \& Tversky, A. (1973). On the psychology of prediction. Psychological Review, $80,237-251$.

Khatri, N., \& Ng, H. A. (2000). The role of intuition in strategic decision making. Human Relations, 53, 57-86.

Kinchin, I. M., Cabot, L. B., \& Hay, D. B. (2008). Visualising expertise: towards an authentic pedagogy for higher education. Teaching in Higher Education, 13, 315-326.

King, L., \& Mcleod Clark, J. (2002). Intuition and the development of expertise in surgical ward and intensive care nurses. Journal of Advanced Nursing, 37, 322-329.

Klein, G. (1998). Sources of power. How people make decisions. Cambridge: MIT Press.

Klein, G. (2003). Intuition at work. New York: Doubleday.

Kolodner, J. L. (1983). Towards an understanding of the role of experience in the evolution from novice to expert. International Journal of Man-Machine Studies, 19, 497-518.

Lakoff, G., \& Johnson, M. (2003). Metaphors we live by ( $2^{\text {nd }}$ ed.). Chicago: University of Chicago Press.

Lephronon, J., \& Patel, V. L. (1995). Decision making strategies for telephone triage in emergency medical services. Medical Decision Making, 15, 240-253.

Levinas, E. (1973). The theory of intuition in Husserl's phenomenology. Evanston: Northwestern University Press.

Lunn, J. H. (1948). Chick sexing. American Psychologist, 36, 280-287.

McNiel, D. E., Sandberg, D. A., \& Binder, R. L. (1998). The relationship between confidence and accuracy in clinical assessment of psychiatric patients' potential for violence. Law and Human Behaviour, 22, 655-669.

Myers, D. G. (2002). Intuition. Its powers and perils. New Haven: Yale University Press.

Newell, B. N., Wong, K. Y., Cheung, J. C. H., \& Rakow, T. (2009). Think, blink or sleep on it? The impact of modes of thought on complex decision making. The Quarterly Journal of Experimental Psychology, 62, 707-732. 
Osho, B. (2002). Intuition: Knowing beyond logic. New York: St. Martin's Press.

Peters, J. T., Hammond, K. R., \& Summers, D. A. (1974). A note on intuitive vs analytic thinking. Organizational Behavior and Human Performance, 12, 125-131.

Plessner, H., Betsch, C., \& Betsch, T. (Eds.). (2008). Intuition in judgment and decision making. New York: Lawrence Erlbaum.

Reber, A. S. (1989). Implicit learning and tacit knowledge. Journal of Experimental Psychology: General, 118, 219-235.

Reber, A. S. (1993). Implicit learning and tacit knowledge. An essay on the cognitive unconscious. Oxford: Oxford University Press.

Reyna, V. F., Lloyd, F. J., \& Brainerd, C. J. (2003). Memory, development, and rationality: An integrative theory of judgment and decision making. In S. L. Schneider \& J. Shanteau (Eds.), Emerging perspectives on judgment and decision research (pp. 201-245). Cambridge: Cambridge University Press.

Robinson, L. A. (2006). Trust your gut. How the power of intuition can grow your business. Chicago: Kaplan.

Sadler-Smith, E. (2008). Inside intuition. London: Routledge.

Sadler-Smith, E. (2010). The intuitive mind. West Sussex: Wiley.

Sadler-Smith, E., \& Shefy, E. (2004). The intuitive executive: understanding and applying 'gut feel' in decision-making. Academy of Management Executive, 18(4), 76-91.

Salmela, J. H., \& Moraes, L. C. (2003). Development of expertise. The role of coaching, families, and cultural contexts. In J. L. Starkes \& K. A. Ericsson (Eds.), Expert performance in sports. Advances in research on sport expertise (pp. 275-294). Champaign: Human Kinetics.

Sanbonmatsu, D. M., Posavac, S. S., \& Stasney, R. (1997). The subjective beliefs underlying probability overestimation. Journal of Experimental Social Psychology, 33, 276-295.

Schroeder, C. H. (1933). How to tell the baby chick's sex. Everybody's Poultry Journal, 289, $293-297$.

Selten, R. (2002). What is bounded rationality? In G. Gigerenzer \& R. Selten (Eds.), Bounded rationality. The adaptive toolbox (pp. 13-35). Cambridge: MIT Press.

Sinclair, M. (Ed.). (2011). Handbook of intuition research. Cheltenham: Edward Elgar.

Shaffer, D. M., \& McBeath, M. K. (2002). Baseball outfielders maintain a linear optical trajectory when tracking uncatchable fly balls. Journal of Experimental Psychology: Human Perception and Performance, 28, 335-348.

Simon, H. A. (1955). A behavioural model of rational choice. Quarterly Journal of Economics, 69, 99-118.

Simon, H. A. (1957). Models of man. New York: Wiley.

Simon, H. A. (1982). Models of bounded rationality. Cambridge: MIT Press.

Sloman, S. A. (2002). Two systems of reasoning. In T. Gilovich, D. Griffin, \& D. Kahneman (Eds.), Heuristic and biases. The psychology of intuitive judgment (pp. 379-396). Cambridge: Cambridge University Press.

Slovic, P. (2001). Cigarette smokers: Rational actors or rational fools. In P. Slovic (Ed.), Smoking: Risk, perception, and policy (pp. 97-124). Thousand Oaks: Sage.

Slovic, P., Finucane, M. L., Peters, E., \& MacGregor, D. G. (2002). The affect heuristic. In T. Gilovich, D. Griffin \& D. Kahneman (Eds.), Heuristics and biases: The psychology of intuitive judgment (pp. 397-420). Cambridge: Cambridge University Press.

Sternberg, R. J., Forsythe, G. B., Hedlund, J., Horvath, J. A., Wagner, R. K., Williams, W. M., Snook, S. A., \& Grigerenko, E. L. (2000). Practical intelligence in everyday life. Cambridge: Cambridge University Press.

Tomasino, D. E. (2011). The heart of intuition: tools for cultivating intuitive intelligence. In M. Sinclair (Ed.), Handbook of intuition research (pp. 247-260). Cheltenham: Edward Elgar.

Tversky, A., \& Kahneman, D. (1983). Extensional versus intuitive reasoning: The conjunction fallacy in probability judgment. Psychological Review, 90, 293-315. 
Tynjälä, P. (2013). Toward a three P model of workplace learning. A literature review.

Vocations and Learning. Studies in Vocational and Professional Education, 6, xxxXxx.

Ward, P., Hodges, N. J., Williams, A. M., \& Starkes, J. L. (2004). Deliberate practice and expert performance: Defining the path to excellence. In A. M. Williams \& N. J. Hodges (Eds.), Skill acquisition in sport: Research, theory and practice (pp. $231-258$ ). London: Routledge.

Wescott, M. R. (1968). Psychology of intuition. A historical, theoretical, and empirical inquiry. New York: Holt, Rinehart \& Winston.

Weston, W. N. (1927). Intuition. Its office, its laws, its psychology, its triumphs and its divinity. New York: Macoy. 